\title{
Directional homing of glycosylation-modified bone marrow mesenchymal stem cells for bone defect repair
}

\author{
Long Chen ${ }^{1 \dagger}$, Wei Luo ${ }^{1 \dagger}$, Yuanzheng Wang ${ }^{1 \dagger}$, Xiongbo Song ${ }^{1}$, Senlei $\mathrm{Li}^{1}$, Jun $\mathrm{Wu}^{2^{*}}$ and Li Sun ${ }^{{ }^{*}}$
}

\begin{abstract}
Background: One of the greatest challenges for tissue-engineered bone is the low survival rate of locally grafted cells. The cell homing technology can effectively increase the number of these grafted cells, therefore, enhancing the repair of bone defects. Here we explore the effect of fucosylation modification on the directional homing of bone marrow mesenchymal stem cells (BMSCs) and their ability to repair bone defects.

Results: Glycosylated BMSCs expressed high levels of the Sialyl Lewis-X (sLe ${ }^{X}$ ) antigen, which enabled the cells to efficiently bind to $\mathrm{E}$ - and P-selectins and to home to bone defect sites in vivo. Micro-CT and histological staining results confirmed that mice injected with FuT7-BMSCs showed an improved repair of bone defects compared to unmodified BMSCs.

Conclusions: The glycosylation modification of BMSCs has significantly enhanced their directional homing ability to bone defect sites, therefore, promoting bone repair. Our results suggest that glycosylation-modified BMSCs can be used as the source of the cells for the tissue-engineered bone and provide a new approach for the treatment of bone defects.
\end{abstract}

Keywords: Bone marrow mesenchymal stem cells, Glycosylation, Directional homing, Bone defect repair

\section{Background}

Bone defect repair is a complex process regulated by numerous factors. It relies on the recruitment of cells with repair potential from the circulatory system or tissues surrounding the damaged area to the injury site. In response to damage microenvironment-induced cytokines and biomechanical factors, these cells will participate in the repair of bone defects either directly or indirectly. Mesenchymal stem cells (MSCs) are the ideal

*Correspondence: wujun29@mail.sysu.edu.cn; lisun@gzu.edu.cn †Long Chen, Wei Luo, and Yuanzheng Wang contribute equally to this work

${ }^{1}$ Department of Orthopedics, Guizhou Provincial People's Hospital, Guiyang 550000, Guizhou, People's Republic of China

${ }^{2}$ Guangdong Provincial Key Laboratory of Sensor Technology and Biomedical Instruments, School of Biomedical Engineering, Sun Yat-

Sen University, Shenzhen 518107, People's Republic of China source of cells for tissue-engineered bones. Recent studies have shown that tissue-engineered bone generated from MSCs and biomaterials in vitro has a low survival rate after implantation into the sites of bone defects in vivo, and, therefore, is not the ideal repair option. Since MSCs lack the appropriate cell surface receptors involved in adhesion and homing, their homing efficiency from the circulatory system or surrounding tissues to the bone defect sites is also very low [1-4]. Therefore, increasing the number of local MSCs during bone repair in vivo has become an urgent problem in the field of tissue-engineered bone. The solution for this problem is also the key to the applications of MSCs in the treatment of bone-related diseases.

Recently, the delivery of MSCs to target damaged tissues and organs via directional homing to induce tissue repair have become a research hotspot in the field of original author(s) and the source, provide a link to the Creative Commons licence, and indicate if changes were made. The images or other third party material in this article are included in the article's Creative Commons licence, unless indicated otherwise in a credit line to the material. If material is not included in the article's Creative Commons licence and your intended use is not permitted by statutory regulation or exceeds the permitted use, you will need to obtain permission directly from the copyright holder. To view a copy of this licence, visit http://creativecommons.org/licenses/by/4.0/. The Creative Commons Public Domain Dedication waiver (http://creativeco mmons.org/publicdomain/zero/1.0/) applies to the data made available in this article, unless otherwise stated in a credit line to the data. 
regenerative medicine. Similar to the biological processes of tumor metastases spreading to various organs in the body with blood circulation, the directional homing of MSCs also requires the participation of multiple adhesion molecules. By leveraging the interactions between adhesion molecules and their ligands, the MSCs can overcome the blood flow shear force and can home to the target area via blood circulation to participate in the repair of damaged tissues. Several studies have shown that hematopoietic stem cells (HSPCs) - which are also derived from the mesoderm, similar to MSCs-can home to the bone marrow in large numbers in the presence or absence of body injuries [5-7]. However, HSPCs express the ligand structures of homing-related adhesion molecules on their surface, while the adhesion molecules E-selectin and P-selectin are widely expressed on the surface of bone marrow microvascular endothelial cells. As HSPCs reach the surface of microvascular endothelial cells in the bone marrow through blood circulation, the selectins will bind to their ligands one after another, enabling HSPCs to overcome the blood flow shear force. After tethering and rolling on the surface of endothelial cells, chemokines will activate the integrins VLA-4 and VLA-5 to induce adhesion and to promote strong attachment between cells. Finally, HSPCs will pass through the capillaries and enter the bone marrow. As cell adhesion molecules, E- and P-selectins are continuously expressed in capillaries and bone tissues. In response to inflammation or tumor invasion, endothelial cells at the injury site will be stimulated by interleukin-1(IL-1), tumor necrosis factor-alpha (TNF- $\alpha$ ), and other inflammatory factors, leading to the upregulation of E- and P-selectin expression. This will assist the rolling and the adhesion of leukocytes to vascular endothelial cells under laminar flow conditions [8-10]. Among several ligands for selectins, sialylated Lewis oligosaccharide (sialyl-LewisX, or sLe ${ }^{\mathrm{X}}$ ) is one of the smallest antigens that binds to selectins. The carbohydrates on the surface of some cell types are the main structures recognized by selectins and can efficiently mediate the selectin/ligand binding [11-13]. Based on these findings, we hypothesized that increasing the expression of $\mathrm{sLe}^{\mathrm{X}}$ antigen on the surface of MSCs will improve their adhesion to selectins, therefore, allowing the directional homing of MSCs.

HPSCs express CD44, a proteoglycan with galactose linked to the $\alpha$-2,3-sialic acid group, and $\mathrm{N}$-acetylglucosamine linked to the $\alpha$-1,3-fucose group, forming a sialylated $\mathrm{SLe}^{\mathrm{X}}$ structure. Although MSCs have naturally low levels of the $\mathrm{sLe}^{\mathrm{X}}$ antigen, they express another type of another CD44 isoform, with $\mathrm{N}$-acetylglucosamine that lacks $\alpha$-1,3-fucose modification [14, 15]. Fucosyltransferase VII (FuT7), an important tool in protein glycosylation engineering, can catalyze the transfer of fucose residues from GDP-fucose to the receptor and promote the formation of the corresponding glycosidic bond. Based on the structural characteristics of MSC surface receptors and the theory of protein glycosylation, here we propose to attach the $\alpha-1,3$-fucose group to the $\mathrm{N}$-acetylglucosamine in MSCs by inducting the expression of exogenous genes. As a result, new glycoprotein epitopes will be formed and will generate many $\operatorname{sLe}^{\mathrm{X}}$ antigens on the surface of MSCs, enhancing their directional homing ability.

Bone defects caused by trauma, infection, or tumors are clinically very common. The current generally accepted treatment of bone defects is bone transplantation. Bone grafts mainly include autologous, allogeneic, and xenogeneic bone; however, this type of treatment has several limitations, such as limited sources, trauma to the donor site, immunologic rejection, disease transmission, and so on. With the rapid development of materials science and tissue engineering technologies over the past two decades, researchers have generated numerous bone replacement materials using novel methods and approaches. However, the low survival rate of locally grafted cells has resulted in poor internal vascularization of the replacement material and insufficient biological functions, restricting their clinical application. The emergence of cell homing technology provided a new opportunity for the artificial bone replacement materials to repair bone defects. Here in this study we transfected the FuT7 gene into MSCs using lentiviral transfection, to attach the $\alpha-1,3$-fucose group to the $\mathrm{N}$-acetylglucosamine of the CD44 molecule on the surface of MSCs, resulting in the generation of a large number of $\operatorname{sLe}^{\mathrm{X}}$ antigens on cell surfaces. Furthermore, in vitro and in vivo experiments were conducted to explore the effect of glycosylation on the directional homing ability of MSCs, and on repair of bone defects after MSCs homing. These findings will provide a foundation for the application of glycosylation-modified MSCs to repair bone defects.

\section{Results \\ Isolation, extraction, and identification of bone marrow mesenchymal stem cells (BMSCs)}

Primary BMSCs had short fusiform (or spindle-shaped) morphology. After culturing for $6 \mathrm{~d}$, the cells reached more than $70 \%$ confluence, and the rate of cell proliferation increased. When the cell confluence reached over $80 \%$, cells were subcultured. After passaging, the cell morphology started to change into a long spindlelike shape, showing typical "fish-like" and "vortex-like" arrangements (Fig. 1A). Flow cytometry was used to identify cell surface markers. Among them, CD44 and CD105, cell stemness markers, accounted for 83.8 and 83.5\%, respectively, while CD34, the endothelial marker, 

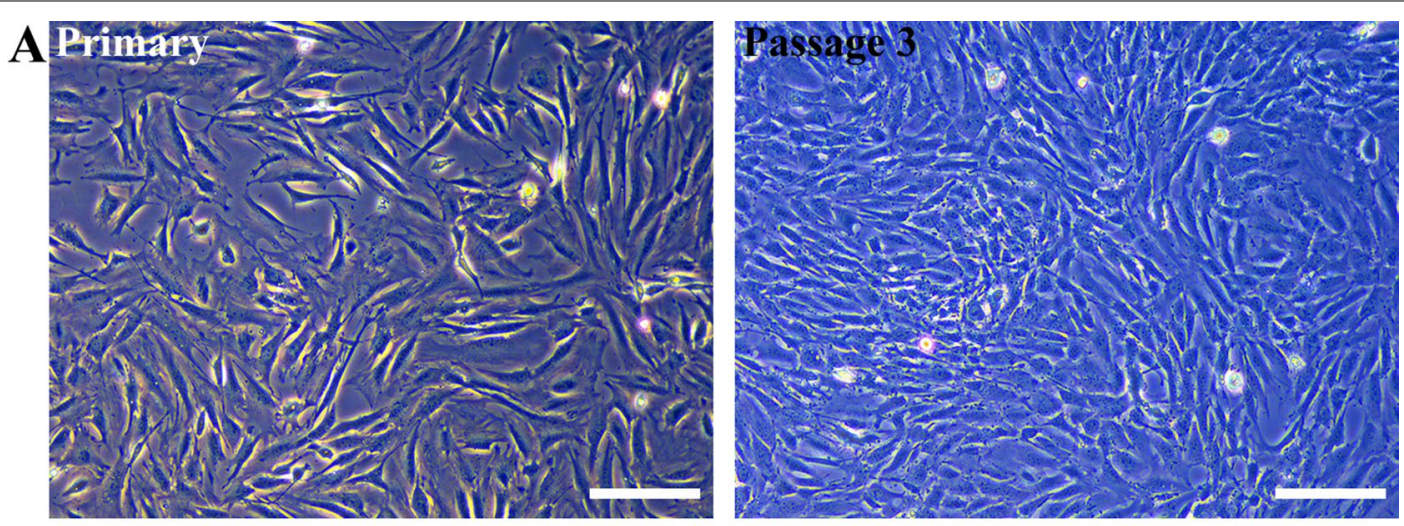

B

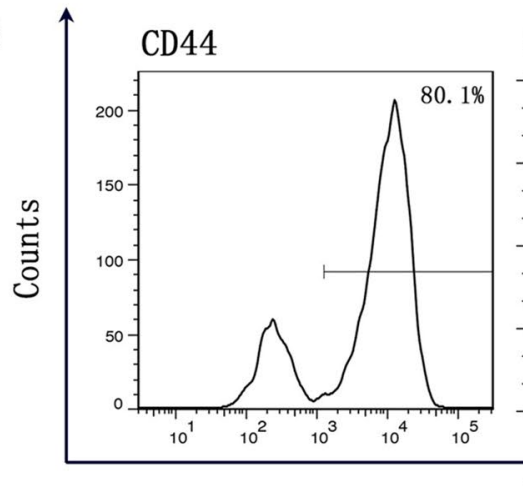

CD105

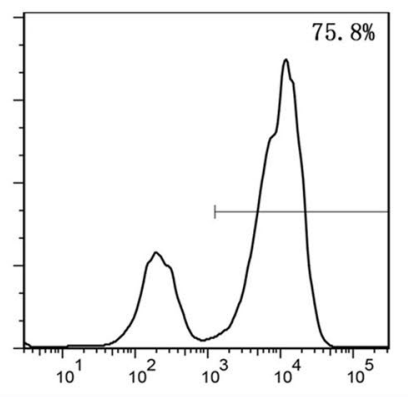

CD34

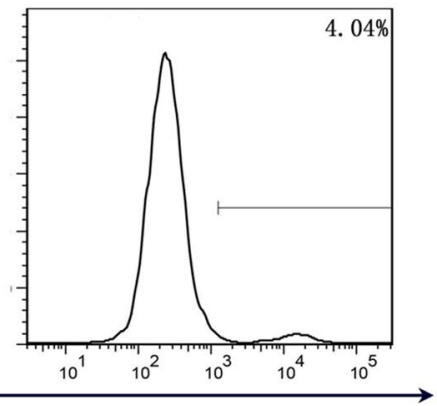

Fluorescence
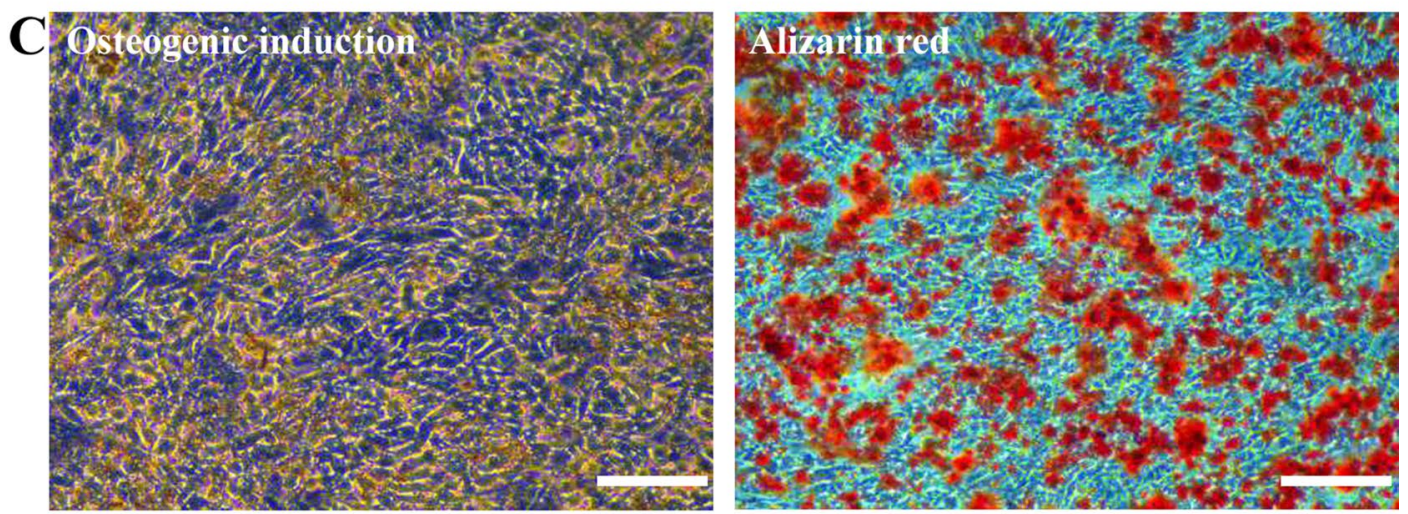

\section{Adipggenic induction}
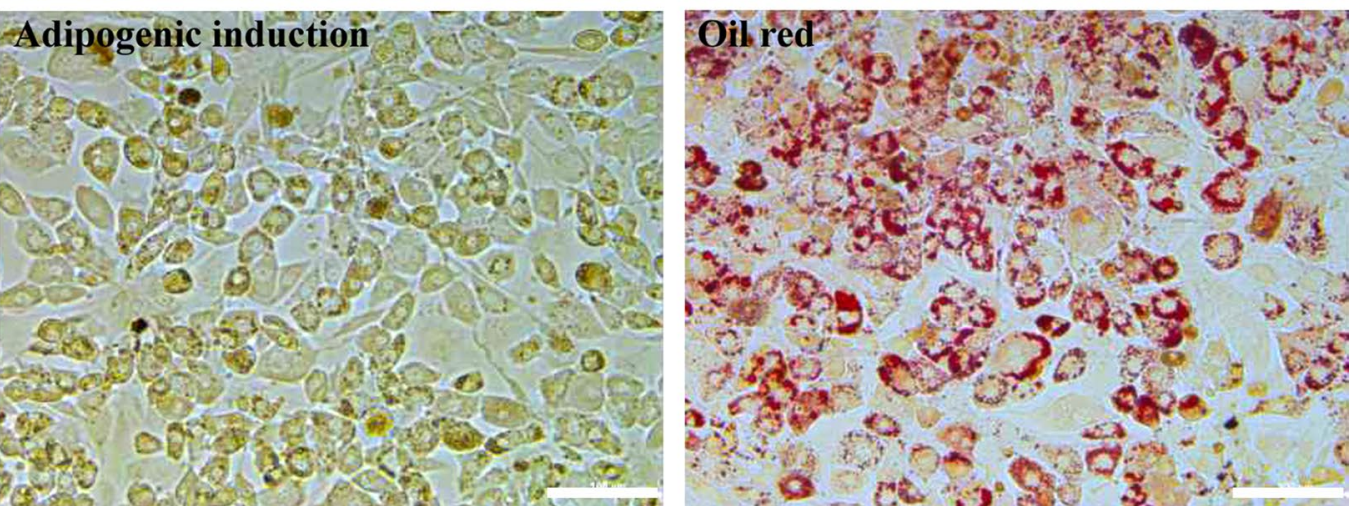

Fig. 1 Identification of BMSCs. Representative images showing A morphology of BMSCs, scale bar = $100 \mu$ m; B Expression of CD44, CD105 and CD34 using flow cytometry; C alizarin red staining (osteogenesis) at day 21, scale bar $=100 \mu \mathrm{m} ; \mathbf{D}$ Oil Red O staining (adipogenesis) at day 14 , scale bar $=100 \mu \mathrm{m}$ 
(See figure on next page.)

Fig. 2 Surface glycosylation modification of BMSCs. Representative images presenting A FuT7 and empty vector expression in BMSCs, scale bar $=100 \mu \mathrm{m}$; B FuT7 and sLeX (CD15S) for surface glycosylation modification of BMSCs by western blotting; C relative gene expression of FuT7 for surface glycosylation modification of BMSCs, ${ }^{* *} p<0.01$; D cell proliferation analysis as shown by CCK-8 for FuT7-BMSCs and BMSCs, ${ }^{\#} p>0.05$; E alizarin red staining (osteogenesis) at day 21 for FuT7-BMSCs and BMSCs, scale bar $=200 \mu \mathrm{m} ; \mathbf{F}$ relative gene expression of Col I and Runx2 for FuT7-BMSCs and BMSCs, ${ }^{* *} p<0.01,{ }^{*} p>0.05$

accounted for only $0.336 \%$ (Fig. 1B). These results are consistent with the percentages reported in the literature, indicating that cells isolated and cultured in this study were indeed MSCs. Next, the cells were induced using osteogenic and adipogenic media and then stained with Alizarin Red and Oil Red O, respectively. Results showed that both sets of cultures were Alizarin Red and Oil Red $\mathrm{O}$ staining positive, respectively, indicating that these cells possessed both osteogenic and adipogenic differentiation potentials (Fig. 1C and D).

\section{Surface glycosylation modification of BMSCs}

After transfecting the FuT7 lentiviral vectors into cells, both FuT7- and the control (empty vector)-containing cells expressed GFP, confirming the successful transfection of BMSCs and allowing us to observe green fluorescence under the fluorescence microscope (Fig. 2A). Western Blotting showed that the glycosylated BMSCs expressed higher levels of FuT7 and $\mathrm{SLe}^{\mathrm{X}}$ (CD15S) proteins compared to the empty vector BMSCs and unglycosylated BMSCs (Fig. 2B). The RT-PCR demonstrated that glycosylated BMSCs expressed higher gene expression levels of FuT7 compared to empty vector BMSCs and unglycosylated BMSCs (Fig. 2C). The CCK- 8 assay showed that glycosylation did not have any effect on the proliferation of MSCs $(p>0.05)$ (Fig. 2D). To evaluate whether glycosylation affected the osteogenic ability of these cells, cultures were assessed by Alizarin Red staining and by PCR. Alizarin red staining allowed us to detect the formation of mineralized nodules by either glycosylated BMSCs or untreated BMSCs. Our results demonstrated that both groups displayed good osteogenic differentiation potential and glycosylation did not have an effect on mineralized nodule formation (Fig. 2E). The real-time fluorescent PCR confirmed that there were no significant differences in the expression of osteogenic genes Col1 and Runx2 $(p>0.05)$ between glycosylated BMSCs and untreated BMSCs (Fig. 2F).

Transwell cell migration assay indicated that TNF- $\alpha$ stimulated MMECs to produce E- and P-selectins, inducing the migration of glycosylated BMSCs. Furthermore, this migration ability of BMSCs was significantly improved by glycosylation $(p<0.05)$ (Fig. 3A). The static adhesion abilities of glycosylated BMSCs and MMECs were evaluated by the flushing strength of PBS. Our results showed that the static cell adhesion abilities of glycosylated BMSCs to MMECs were significantly higher compared to the control group or the negative control group $(p<0.05)$ (Fig. 3B). The binding capacities of glycosylated BMSCs to E- and P- selectins were also detected by flow cytometry. Our results demonstrated that the binding capacity of glycosylated BMSCs to Eand P- selectins was stronger than of the control group or the blank group: the binding capacity to E-selectin was $84.6 \%$, and the binding capacity to P-selectin was $76.7 \%$ (Fig. 4).

\section{Detection of the directional homing ability of glycosylated BMSCs using bone defect mouse model}

The results of the bone marrow flushing method suggested that glycosylation treatment significantly improved the homing ability of BMSCs to the bone defect site in vivo $(p<0.05)$ (Fig. 5). To further explore the directional homing ability of glycosylated BMSCs in the mouse model of bone defect, the in vivo imaging method was used. Results showed that glycosylation significantly improved the directional homing ability of BMSCs to reach the bone defect site in our mouse model $(p<0.05)$ (Fig. 6). Using the 3D femur reconstruction and the cross-sectional scan of the femoral sagittal axis, the Micro-CT results suggested that at days 7 and 14, the glycosylated BMSCs group had smaller defect repair area and higher BV/TV ratio $(p<0.05)$, indicating better bone repair, compared to the other two groups (Fig. 7). The H\&E and Masson staining confirmed that the glycosylated BMSCs group showed better bone defect repair properties, since the trabecular bone and the dark blue calcium nodules were more apparent than in the other two groups. Furthermore, the thin layer of callus had covered almost the entire bone defect area in glycosylated BMSCs group (Fig. 8).

\section{Discussion}

In 1983, Gallatin et al. reported for the first time that lymphocytes circulating in the blood could selectively enter secondary lymphoid organs, naming this process as lymphocyte "homing" [16]. Since then, "homing" has been used to describe the process during which cells (especially white blood cells) migrate directionally towards and colonize specific target tissues. In recent years, with the rise of stem cell therapy, this concept has been extended to a variety of cells, including MSCs. The 

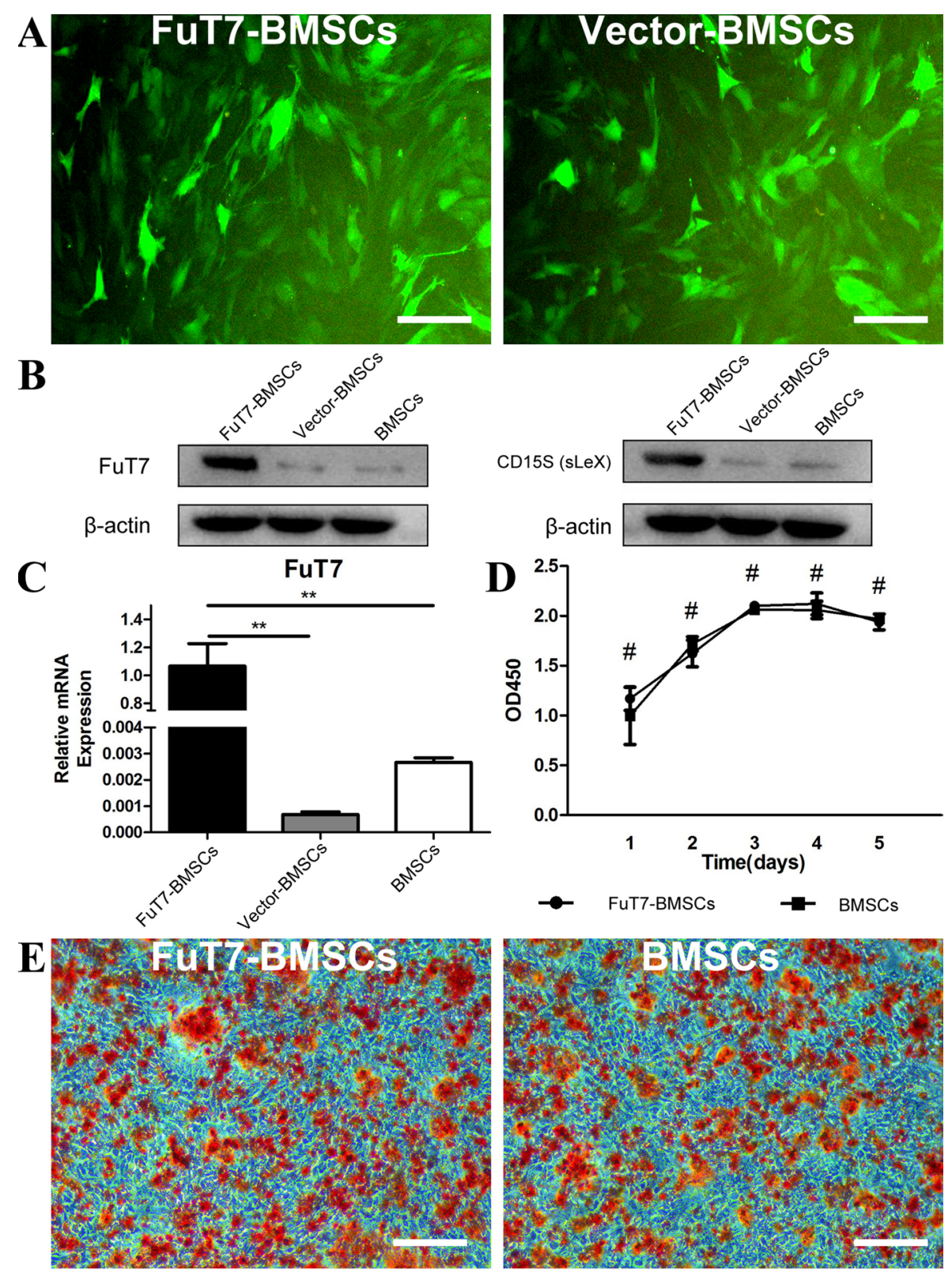

$\mathbf{F}$

Col I
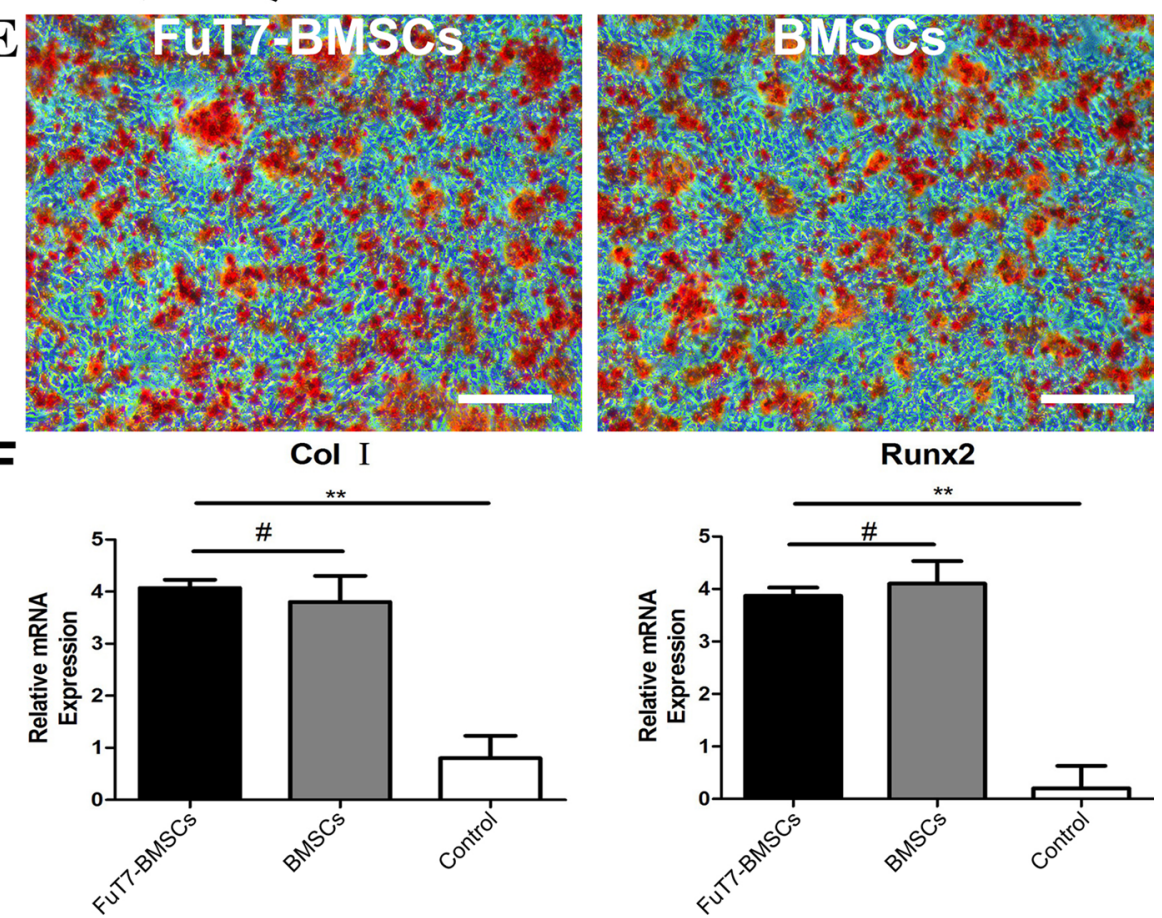

Fig. 2 (See legend on previous page.) 


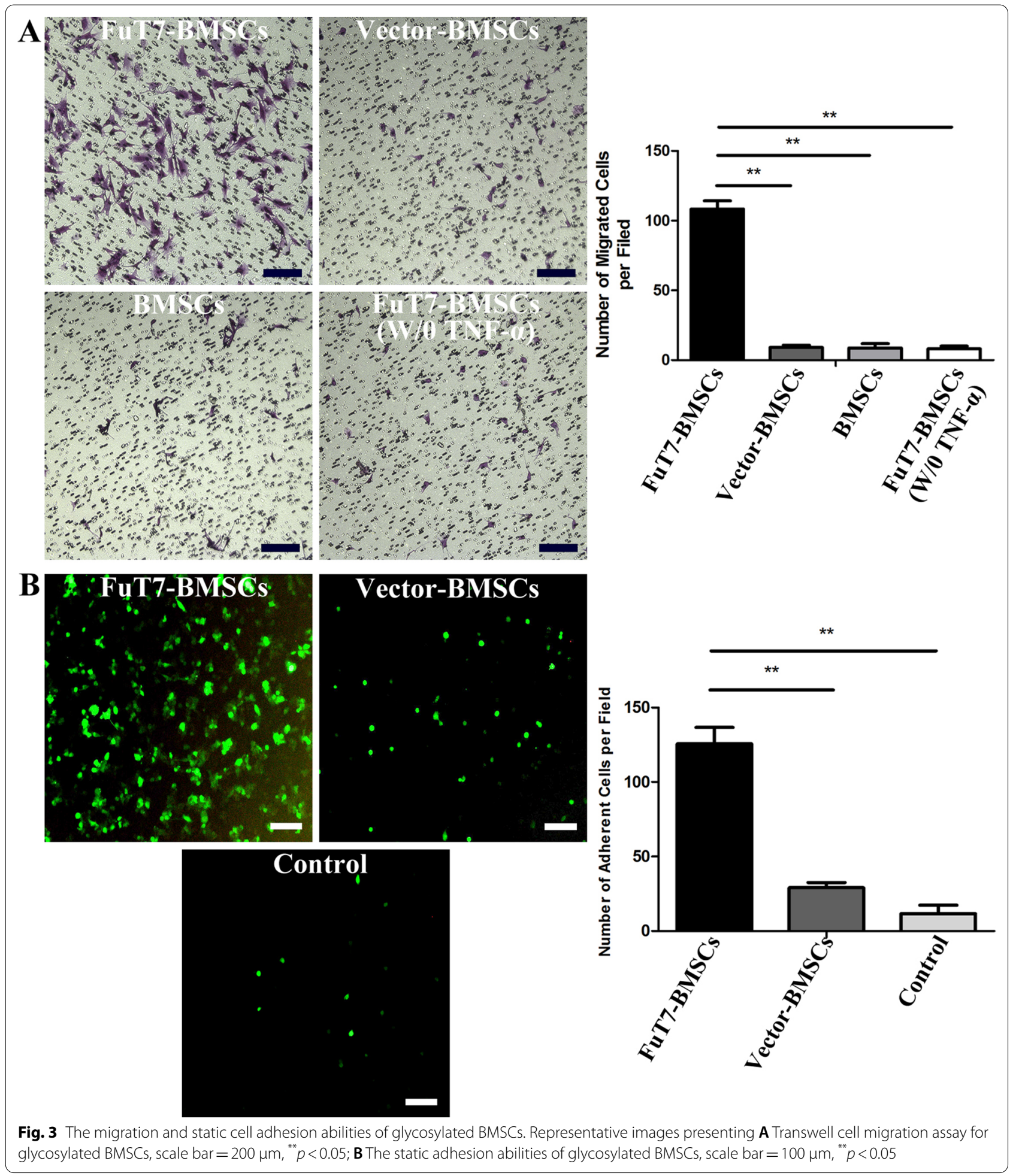

directional homing of MSCs refers to the process, driven by various factors, during which autologous or exogenous MSCs migrate through the vascular endothelium to target tissues or organs, and colonize. MSCs possess multidirectional differentiation potential and the ability to maintain body homeostasis, which are the keys to their capabilities in promoting tissue repair and regeneration. When local tissues are subjected to severe and 


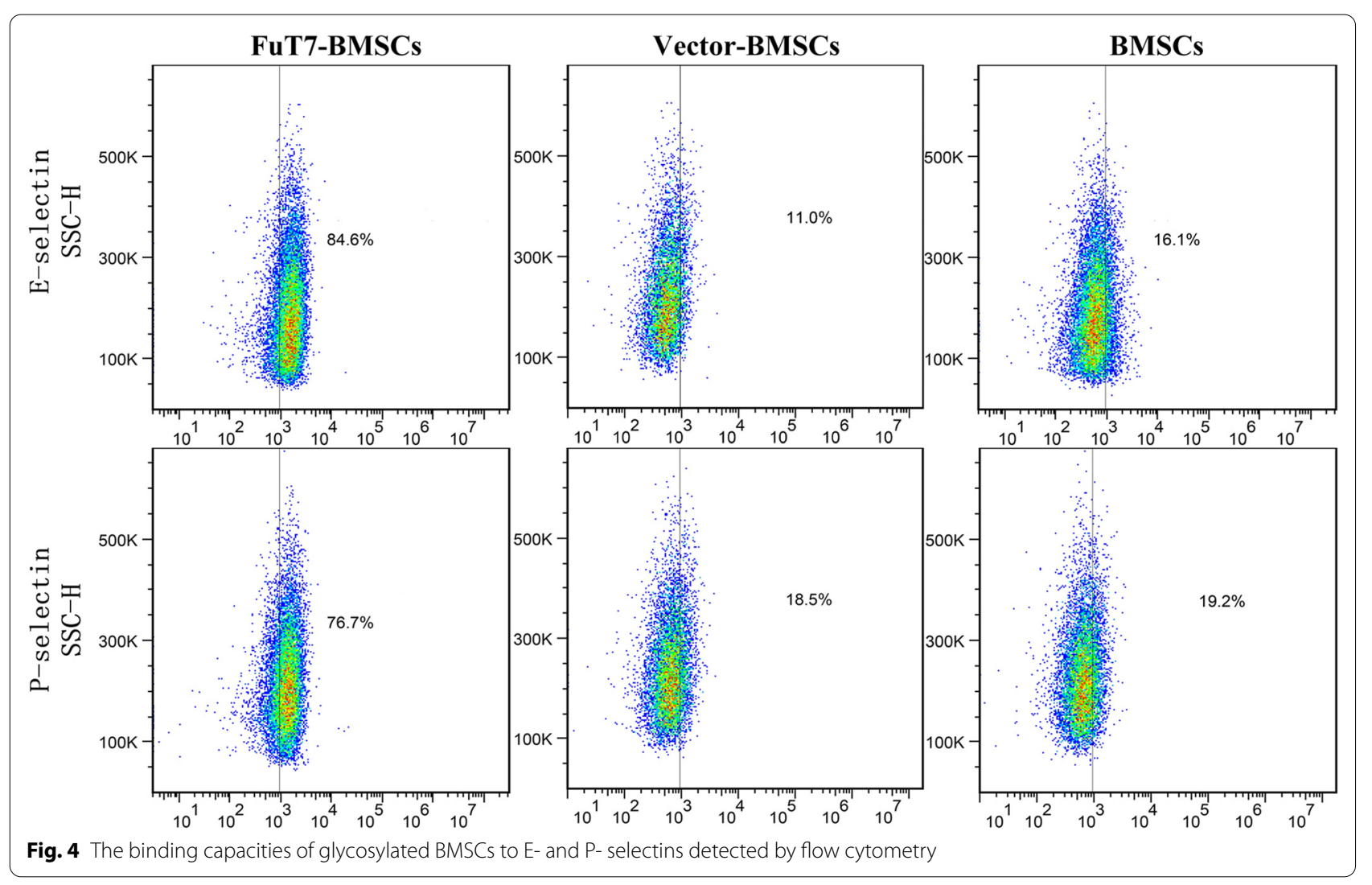

irreversible injuries, MSCs are often required to home to the injury sites in order to provide necessary cells to initiate tissue repair [17]. Since MSCs lack cell surface antigens related to adhesion and homing, their homing efficiency to migrate from the circulatory system or surrounding tissues to the injury site is relatively low. With the continuous development of tissue engineering, various stem cell technologies have been applied to enhance the homing ability of MSCs, thereby providing new methodologies for the repair of various tissue and organs. For bone tissue engineering, stem cell homing based on scaffold features and cell modification are most likely to enhance the homing ability of MSCs. Scaffold is one of the three key elements for bone tissue engineering, and it can be designed and modified by chemical and physical methods to recruit MSCs to reach the bone defect area. For cell modification, it mainly includes three technologies to enhance the homing ability of MSCs: magnetic guidance, genetic modification and cell surface engineering.

The homing process of MSCs can be divided into five main steps: tethering/rolling, activation, arrest, transmigration, and migration. For these five homing steps, the strategies to enhance the homing ability of MSCs include: (1) magnetic guidance; (2) gene modification; (3) cell surface modification; (4) priming; and (5) modification of target tissues [18]. The cell surfaces of almost all organisms are covered with different types of sugar molecules. Glycosylation is a process that modifies the sugar chains on the protein surface via enzymatic reactions, leading to changes in protein function [19]. In this study, a lentiviral vector carrying a FuT7 gene was constructed, and then transfected into MSCs to link the $\alpha$-1,3-fucose group to the $\mathrm{N}$-acetylglucosamine of the $\mathrm{CD} 44$ molecule on the surface of MSCs, therefore, transforming them into cells with a strong affinity for selectins. After the cells were stably transfected, Western Blotting and RT-PCR confirmed that glycosylated MSCs expressed high levels of FuT7, both on protein and gene levels. Western Blotting was also used to confirm the high expression of the $\mathrm{sLe}^{\mathrm{X}}$ antigen. Using flow cytometry, static adhesion, and Transwell migration experiments, we demonstrated that the glycosylated MSCs displayed stronger adhesion and chemotaxis to E- and P-selectins, supporting our hypothesis. To further verify the directional homing effect of glycosylated MSCs in vivo, we performed the bone marrow flushing and in vivo imaging experiments using the drill-hole bone defect mouse model. MSCs labeled with green fluorescence (GFP) and firefly fluorescence were injected into mice with bone defects through the tail vein. 


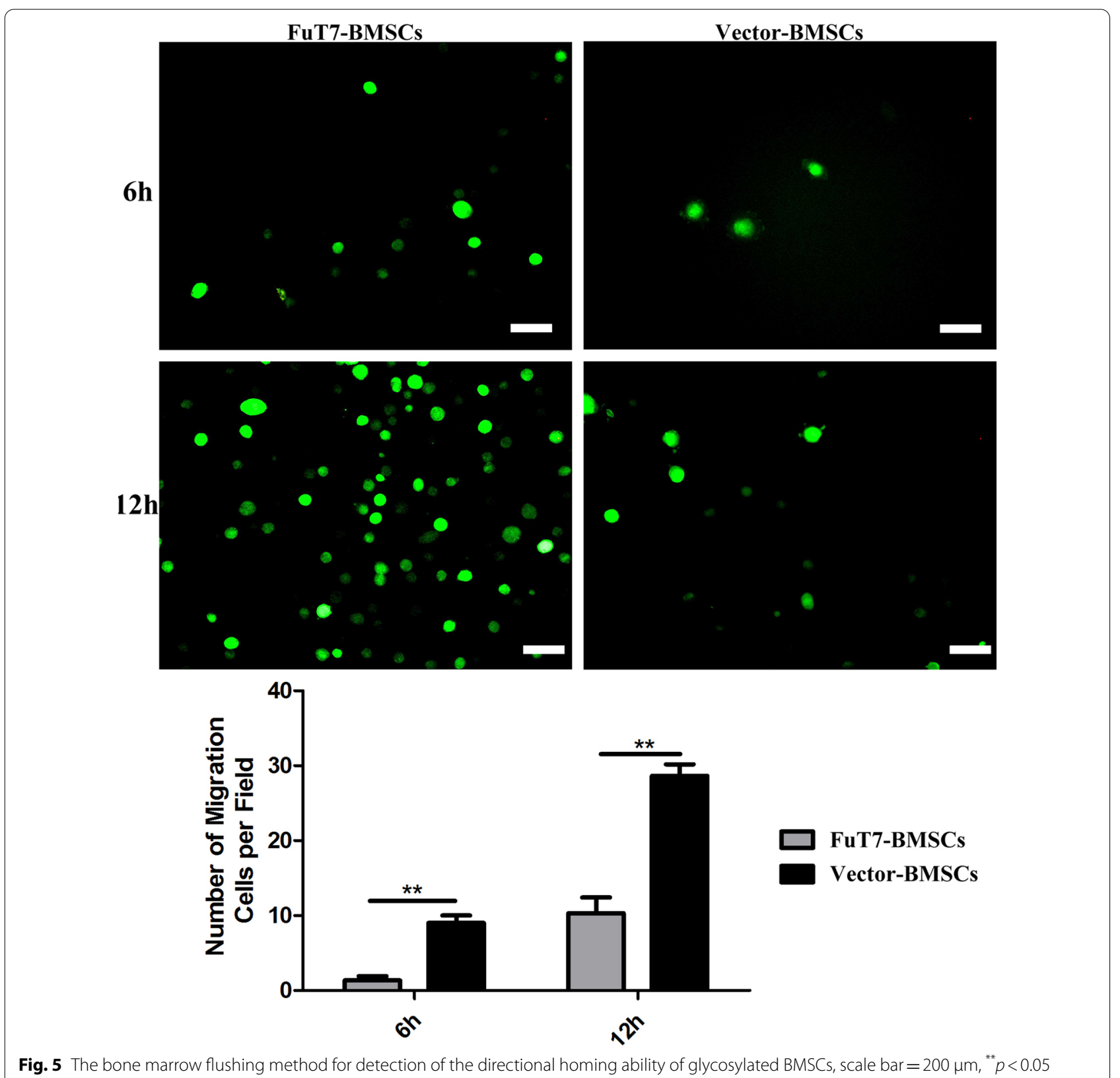

The number of homing cells was measured at 6 and $12 \mathrm{~h}$, respectively. These two methods further confirmed that glycosylation enhanced the directional homing ability of MSCs. Other methods, such as chemical modification or genetic modification, to enhance the directional homing ability of cells have also been reported [20-22]. Although the homing ability of cells to the injured site could be enhanced, these strategies often have several limitations, such as complex modification methods, poor cell stability after modification, damage to the original biological functions of the cells, and potential carcinogenic risk.
Therefore, in terms of safety and feasibility, we believe that the cell glycosylation modification method is more advantageous compared to the other methods.

The bone repair process usually undergoes several specific stages: inflammatory hematoma stage, soft callus formation stage, hard callus formation stage, and callus remodeling stage. In the inflammatory stage, a hematoma usually occurs within 7 days after injury. During that stage, a large number of inflammatory cells and inflammatory factors (such as IL-1, TNF- $\alpha$, among others) is accumulated at the defect site. These inflammatory 

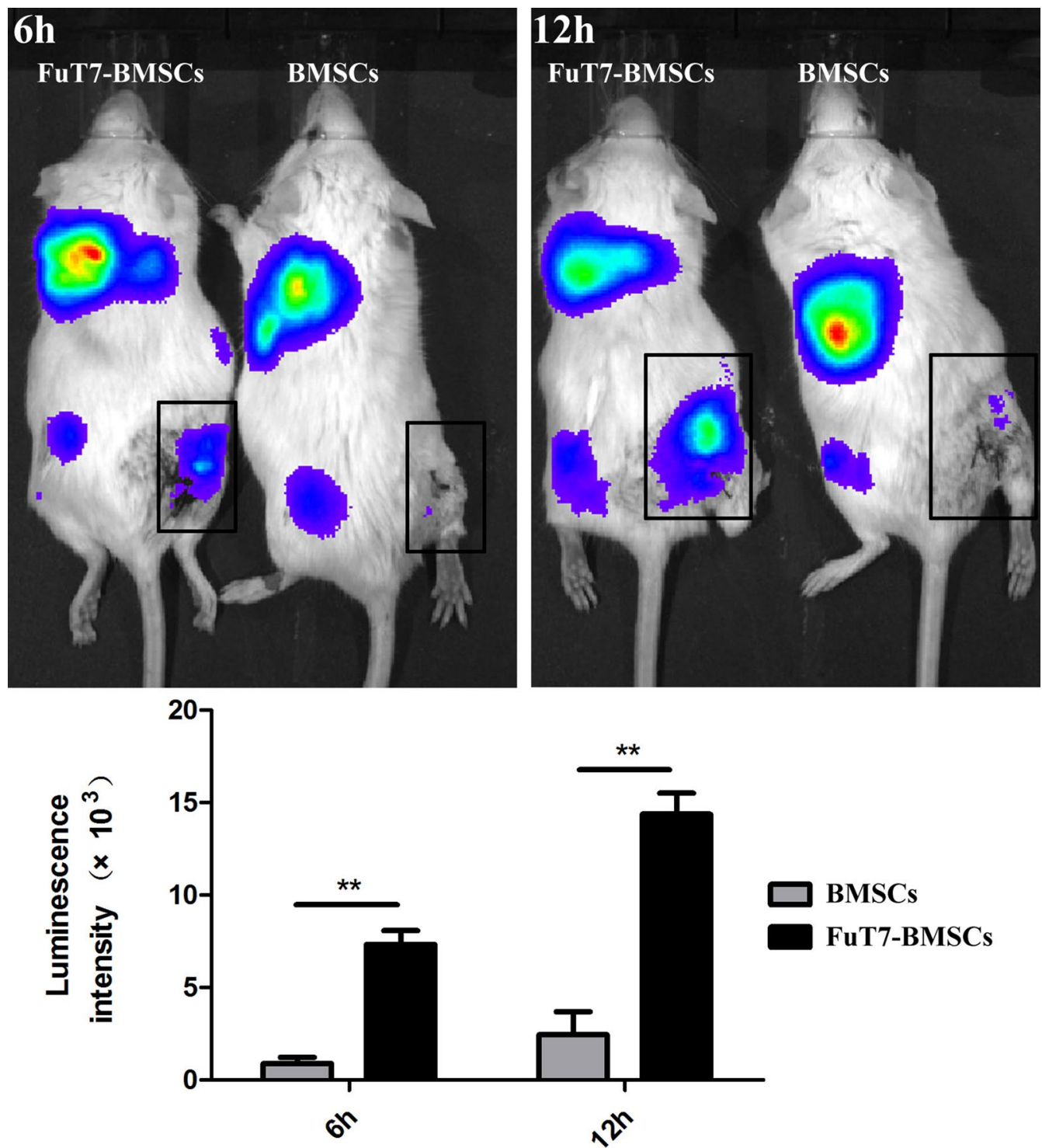

Fig. 6 The in vivo imaging method for detection of the directional homing ability of glycosylated BMSCs, ${ }^{* *} p<0.05$

factors will stimulate vascular endothelial cells to express high levels of selectins. Around day 14 after bone injury, the repair process will progress to the soft callus formation stage. Since the formation mechanism of the long bone is endochondral ossification, large numbers of chondrocytes will begin to appear and will be continuously replaced by osteoblasts. Based on the Micro-CT scans of the femur defect at days 7 and 14, we observed that the glycosylated MSCs group had a smaller defect area and higher BV/TV ratio. Furthermore, the histological staining showed that in the glycosylated MSCs group, chondrocytes were congregating around the bone defect, and a considerable amount of callus was observed covering the defect surface during the early stage. To further explore whether the surface glycosylation modification of MSCs can affect their osteogenic ability, osteogenic differentiation experiments were performed in vitro. Based on the number of calcified nodules (Alizarin Red staining) and the expression levels of Col1 and Runx2, there was no significant difference in osteogenic potential between surface glycosylation-modified MSCs and untreated MSCs. Furthermore, the CCK-8 assay verified that glycosylation modification had no significant effect on the proliferation of MSCs. Collectively, our results suggest that in vivo, after the modified cells reached the bone defect site via the blood circulation, 


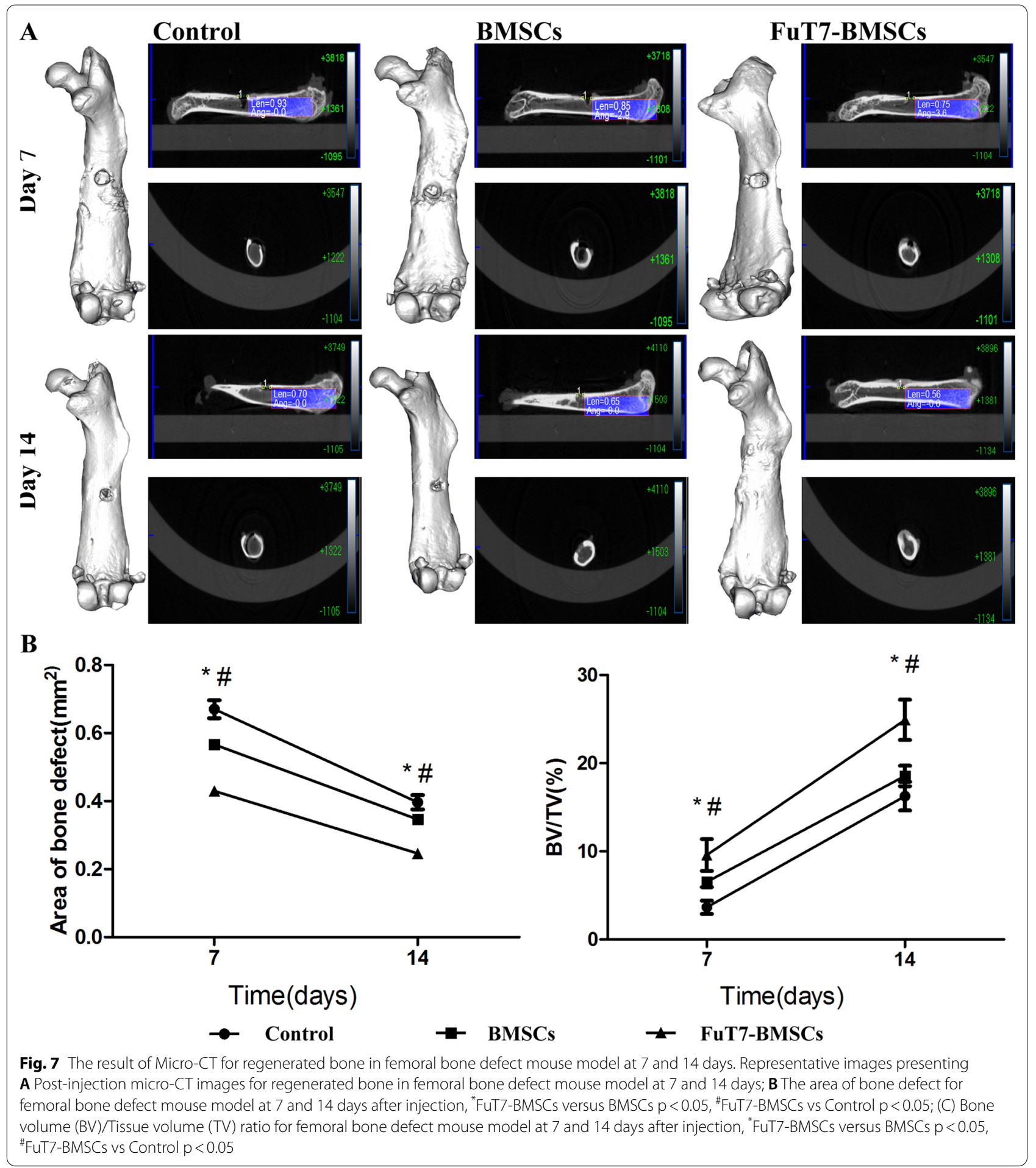

they colonized the endosteum surface, while maintaining their self-proliferation abilities and osteogenic differentiation. Our findings are also consistent with the research reported by Sackstein et al. [14, 15]. Therefore, it is possible that the significantly enhanced bone repair observed in the glycosylation group could be attributed to the increased migration of MSCs to the defect site. These MSCs would produce cytokines that promote bone repair, further stimulating bone healing in the glycosylation group. 

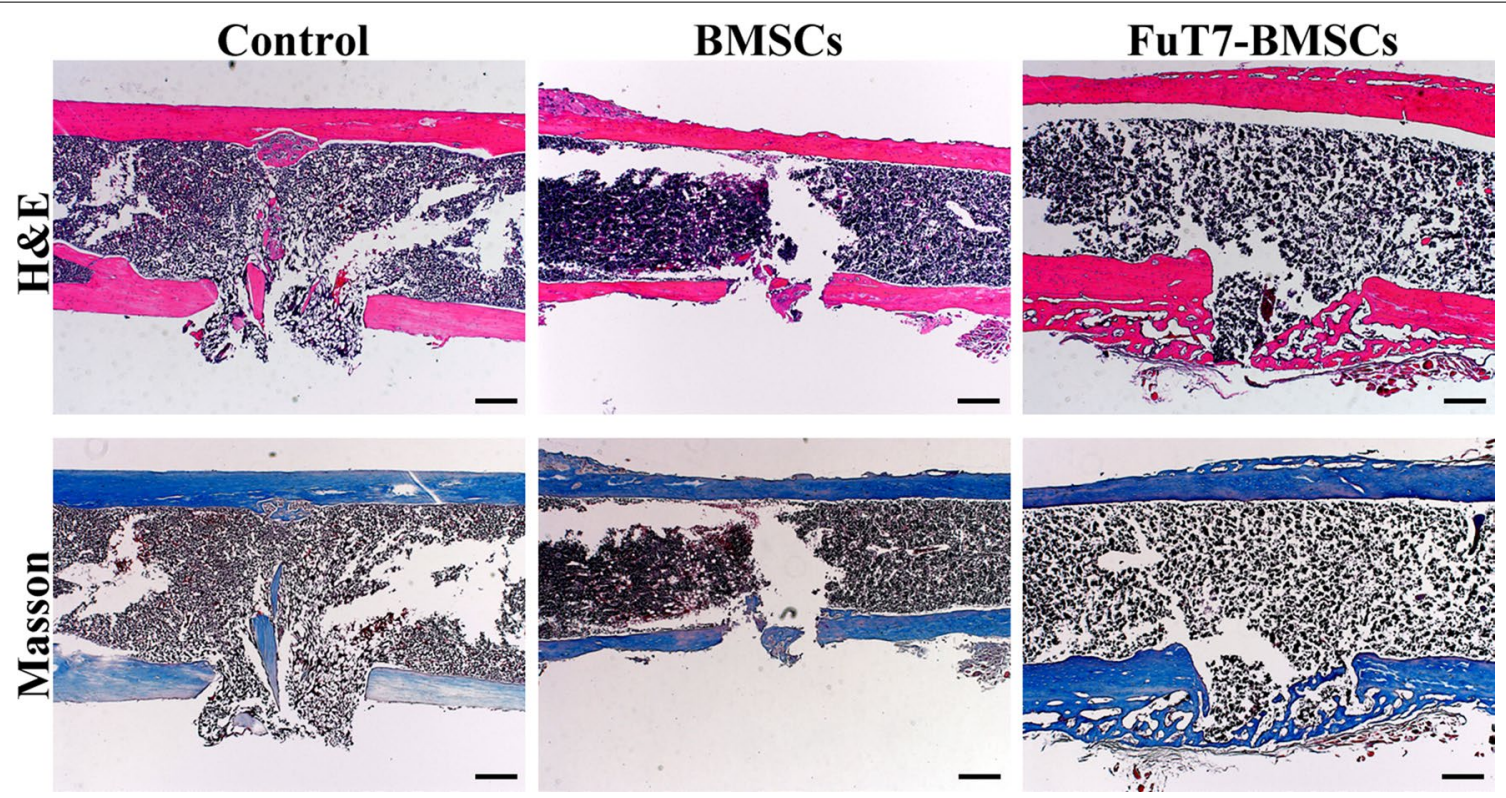

Fig. 8 The H\&E and Masson staining for regenerated bone in femoral bone defect mouse model at 10 days, scale bar $=200 \mu \mathrm{m}$

\section{Conclusions}

In this study, the in vitro glycosylation modification was used to generate sLe $\mathrm{e}^{\mathrm{X}}$ antigens on the surface of MSCs, leading to significantly enhanced binding to $\mathrm{E}$ - and P-selectins. At the same time, this modification did not affect MSC proliferation and osteogenic differentiation potential. In the mouse model of bone defect, the glycosylation modification of MSCs significantly improved the directional homing ability of the cells to the bone defect site, resulting in increased number of homing cells and enhanced bone repair. Therefore, glycosylated MSCs can be utilized as the preferred source of cells for tissueengineered bone, providing a novel approach for treating bone defects, and have broad application potential.

\section{Methods}

\section{Isolation, extraction, and identification of BMSCs}

Six 4-week-old male SPF FVB/N mice were sacrificed by cervical dislocation and then placed into $75 \%$ ethanol solution for $5 \mathrm{~min}$. The bilateral tibia and femur of the mice were dissected out using sterilized surgical instruments in the laminar flow hood. The metaphyses on both sides were cut off using ophthalmic scissors, and a 2-mL syringe containing PBS was used to flush the bone marrow from the long diaphysis into a $15-\mathrm{mL}$ centrifuge tube. The centrifuge tube was then centrifuged at $500 \times g$ for $15 \mathrm{~min}$, the supernatant was discarded, and the cell pellets were resuspended in PBS. The cell concentration was adjusted to $1 \times 10^{8}$ cells $/ \mathrm{mL}$ to prepare the single cell suspension, and then separated using density gradient centrifugation.

The confluent passage P3 cells were collected and the expression of CD44 (eBioscience, CA, USA), CD105 (eBioscience, CA, USA), and CD34 (eBioscience, CA, USA) was detected using flow cytometry. The confluent passage P3 cells were cultured either in osteogenic induction medium or in adipogenic induction medium (Cyagen Biosciences Inc, CA, USA) for 21 or 14 days, respectively. Next, cultures were stained with either Alizarin Red or Oil Red O (Cyagen Biosciences Inc, CA, USA) to verify their osteogenic or adipogenic differentiation potential, respectively.

\section{Surface glycosylation modification of BMSCs}

The pLVX-IRES-ZsGreen 1-PGK-Puro plasmid $(1 \mu \mathrm{g})$ (Genechem, Shanghai, China), DMEM (1 ml) (Hyclone, CA, USA), Lenti-HG Mix $(10 \mu \mathrm{L})$, and HG transgene reagent $(60 \mu \mathrm{L})$ were added into the petri dish to co-transfect the $293 \mathrm{~T}$ cells. After $12 \mathrm{~h}$ of transfection, $100 \times$ Enhancing buffer was added drop-by-drop to promote transfection. After $20 \mathrm{~h}$ of transfection, the medium in the petri dish was replaced. Next, $48 \mathrm{~h}$ after replacing the medium, the cell supernatant was transferred to a $50-\mathrm{ml}$ centrifuge tube and centrifuged at $4500 \times \mathrm{g}$ for $5 \mathrm{~min}$. After that, the supernatant was filtered using a $0.45-\mu \mathrm{m}$ filter and transferred to a new centrifuge tube. The filtrate was then concentrated in batches. The final centrifugation was performed at $4500 \times \mathrm{g}$ for $20 \mathrm{~min}$, and the liquid in the upper layer of the filter was the viral concentrate. 
Table 1 Primer sequences (5'-3') used for RT-PCR

\begin{tabular}{lll}
\hline Gene & Forward & Reverse \\
\hline FuT7 & ATGGAATCGCCCAGTAATACCC & TTTGGCCGGTAGTGGGGAT \\
$\beta$-actin & AACAGTCCGCCTAGAAGCAC & CGTTGACATCCGTAAAGACC \\
\hline
\end{tabular}

The DMEM/F12 complete medium was used to prepare a cell suspension at a density of $3 \times 10^{4}$ cells/ $\mathrm{mL}$, and $100 \mu \mathrm{L}$ of the suspension was pipetted into a 96-well plate. Based on our preliminary experiments, the corresponding amount of virus (Genechem, Shanghai, China) was added, MOI $=$ (virus titer $\times$ virus volume)/number of cells; Polybrene (Sigma, Saint Louis, USA) $(10 \mu \mathrm{g} / \mathrm{mL})$ was also added to screen for infected cells. The cells were cultured for another 2-3 days to maintain cell viability. Cell viability was observed using an inverted microscope. The medium was replaced every day to remove the dead cells. The infection efficiency was observed using a fluorescence microscope, with the green fluorescence indicating successfully infected cells. The same method was utilized to transfect BMSCs with the control (empty vector) virus.

The FuT7-BMSCs, Vector-BMSCs, and untreated BMSCs were washed with PBS, and $200 \mu \mathrm{L}$ of RIPA protein lysis solution containing PMSF (Sigma, Saint Louis, USA) was added to each $25-\mathrm{cm}^{2}$ culture flask. Cells were scraped, transferred into the microcentrifuge tube, and lysed on ice for $30 \mathrm{~min}$. The lysates were then centrifuged at $12,000 \times \mathrm{g}$ for $10 \mathrm{~min}$ at $4{ }^{\circ} \mathrm{C}$. The FuT7 and sLe ${ }^{\mathrm{X}}$ (Antibody, Abcam, MA, USA) concentration of the supernatant was measured, SDS-PAGE gel electrophoresis (Beyotime Biotechnology, Shanghai, China) was performed, followed by membrane transfer, antibody incubation, exposure, and analysis.

FuT7-BMSCs, Vector-BMSCs, and untreated BMSCs were washed with PBS. The Trizol reagent was used to extract the intracellular RNA, and a reverse transcription kit (Takara Bio Inc, Japan) was used for reverse transcription. The SYBR ${ }^{\circledR}$ Premix Ex Taq II kit (Takara Bio Inc, Japan) was used to evaluate FuT7 gene expression by the IQ5 real-time PCR system. The primer sequences are listed in Table 1.

The passage P3 FuT7-BMSCs and BMSCs were used in these experiments. After trypsin digestion, cells were seeded into 96-well plates at $1 \times 10^{5}$ cells $/ \mathrm{mL}, 100 \mu \mathrm{L} /$ well. Five groups of cells corresponding to day 1, 2, 3, 4, and 5 were prepared. The 96-well plates from the corresponding number of days were taken out and $10 \mu \mathrm{L}$ of CCK reagent (MedChemExpress, NJ, USA) was added to each well according to the CCK- 8 manual. Next, the 96-well plates were incubated in a $37^{\circ} \mathrm{C}$ incubator for
Table 2 Groups of the in vitro migration experiment of glycosylated BMSCs

\begin{tabular}{lll}
\hline Group & Upper insert & Lower insert \\
\hline Group 1 & FUT7-BMSCs & MMECs + TNF-a \\
Group 2 & BMSCs & MMECs + TNF-a \\
Group 3 & FUT7-BMSCs & MMECs \\
Group 4 & Vector-BMSCs (empty vector) & MMECs + TNF-a \\
\hline
\end{tabular}

$2 \mathrm{~h}$. Optical density of each well was measured using a microplate reader at a wavelength of $450 \mathrm{~nm}$.

The mouse microvascular endothelial cell (MMEC) (MT Bio Inc, Shanghai, China) suspension $\left(4 \times 10^{4}\right.$ cells/ $\mathrm{mL})$ was pipetted into 24 -well plates, at $600 \mu \mathrm{L}$ per well. Next, to stimulate the MMECs, TNF- $\alpha(10 \mathrm{ng} / \mathrm{mL}$ ) (Sino Biological Inc, Beijing, China) was added to each well of the culture plates and the plates were placed into the cell culture incubator for $6 \mathrm{~h}$. The Transwell inserts were placed into the 24 -well plates, $5 \times 10^{3}$ cells $/ \mathrm{mL}$ of different BMSCs were added to each insert (Table 2, Additional file 1: Figure S1), and cells were then incubated in a $37{ }^{\circ} \mathrm{C}$ incubator. After $12 \mathrm{~h}$ of incubation, the Transwell inserts for each group were taken out and washed three times with PBS. The cells were fixed with $4 \%$ paraformaldehyde for $30 \mathrm{~min}$ and then washed three times with PBS. The cells on the Transwell insert membrane were stained with crystal violet solution $(500 \mu \mathrm{L}$ per well) for $30 \mathrm{~min}$. The top layer of the insert membrane was washed under running water to remove the dye while avoiding touching the insert bottom. The inside of the insert was dried using a cotton swab, and the cells were observed, imaged, and counted under a microscope.

The passage P3 MMECs were seeded into 96-well plates in the complete medium containing $25 \mathrm{ng} / \mathrm{mL}$ TNF- $\alpha$. The plates were incubated at $37{ }^{\circ} \mathrm{C}$ and $5 \% \mathrm{CO}_{2}$ for $6 \mathrm{~h}$; after that, the medium was removed. The BMSCs from each group were prepared as single-cell suspensions, added to each well of the 96-well plates at $1 \times 10^{3}$ cells/well, and the plates were incubated for $1 \mathrm{~h}$. Next, the plates were taken out, the culture medium was aspirated and discarded, and the wells were washed three times with PBS. The cells were then observed, imaged, and counted under a fluorescent microscope. (Three random visual fields were selected for each group; the empty virus transfection group was used as the control group, and the group without TNF- $\alpha$ stimulation was used as the negative control group).

The BMSCs were divided into three groups: FuT7 group, empty vector transfection group (Vector), and untreated group. These three groups of BMSCs were resuspended in $1 \%$ BSA to prepare cell suspensions at $2 \times 10^{6}$ cells $/ \mathrm{mL}$. According to the manufacturer's 
Table 3 Primer sequences $\left(5^{\prime}-3^{\prime}\right)$ used for RT-PCR

\begin{tabular}{lll}
\hline Gene & Forward & Reverse \\
\hline Coll & GCTCCTCTTAGGGGCCACT & ATTGGGGACCCTTAGGCCAT \\
Runx2 & GACTGTGGTTACCGTCATGGC & ACTTGGTTTTTCATAACAGCGGA \\
GAPDH & AGGTCGGTGGAACGGATTTG & GGGGTCGTTGATGGCAACA \\
\hline
\end{tabular}

protocol, $10 \mu \mathrm{g} / \mathrm{mL}$ CD62P (recombinant human P-selectin) (R\&D, MINN, USA) and $2 \mu \mathrm{g} / \mathrm{mL}$ CD62E (recombinant human E-selectin) (R\&D, MINN, USA) were added to each $100 \mu \mathrm{L}$ of cell suspension, and cells were then incubated for $1 \mathrm{~h}$ at $37^{\circ} \mathrm{C}$ in the dark. Another $5 \mu \mathrm{L}$ of CD62E-PE and $5 \mu \mathrm{L}$ of CD62P-APC were added to each group of cells, followed by incubation at $4{ }^{\circ} \mathrm{C}$ in the dark for $30 \mathrm{~min}$. The cells were washed twice using centrifugation and analyzed on a flow cytometer.

The passage P3 glycosylated BMSCs and untreated BMSCs were cultured for two weeks in the osteogenic induction medium and then stained with Alizarin Red. The number of calcified nodules in random visual fields was determined using the microscope and then compared between these two groups to evaluate their osteogenic potential.

The passage P3 glycosylated BMSCs and untreated BMSCs were cultured for two weeks in the osteogenic induction medium (BMSCs cultured without osteogenic induction served as the negative control group). Total RNA was extracted from all three groups of BMSCs, using the same RNA extraction method as described previously. Reverse transcription and PCR were also performed as described previously. The primer sequences used are listed in Table 3.

\section{Detection of the directional homing ability of glycosylated BMSCs in mid-femoral bone defect mouse model}

SPF FVB/N male mice (8-week-old) were injected intraperitoneally with $4 \%$ chloral hydrate for anesthesia. Next, the right lower limb skin was prepared and disinfected. The skin over the middle section of the right thigh was cut open $(\sim 0.5 \mathrm{~cm})$ and the thigh muscles were bluntly separated, exposing the middle section of the femur. After expanding the surrounding muscles, a dental micro drill with a 1.0-mm drill bit was used to drill through the cortical bone on both sides of the femur perpendicularly. After the bone defect was successfully introduced, local disinfection was performed, and the incision was then closed layer by layer.

Twelve $\mathrm{FVB} / \mathrm{N}$ mice were subjected to the same bone defect procedures as described above. The mice were divided into the FuT7-BMSCs group and the Vector-BMSCs group ( $n=6$ /group). Green fluorescence was observed from the cells in both groups. The cell concentration was adjusted to $1 \times 10^{7}$ cells $/ \mathrm{mL}$. A $1-\mathrm{mL}$ syringe was used to aspirate the cell suspension and inject it into the mouse through the tail vein. Mice were injected with $300 \mu \mathrm{L}$ of the cell suspension per mouse and then sacrificed at 6 and $12 \mathrm{~h}$. The bone section $0.5 \mathrm{~cm}$ above and below the right femoral defect was dissected out and both ends of the bone were cut off. A syringe containing $1 \mathrm{~mL}$ of the DMEM/F12 complete medium was used to wash the retained diaphysis repeatedly. The washed-out cells were plated in a 24-well plate and placed into a cell culture incubator for $1 \mathrm{~h}$. After $1 \mathrm{~h}$, the culture plate was taken out from the incubator and placed under a fluorescence microscope for observation. Three random visual fields were selected from each well to image, count, and calculate the results.

The firefly luciferase control lentiviruses were used to transfect the FuT7-BMSCs and untreated BMSCs using the same approach as described above. After successful transfection, two groups of passage P2 cells were taken and the cell concentration was adjusted to $1 \times 10^{7}$ cells $/ \mathrm{mL}$. Mice with femoral bone defects were injected through the tail vein ( $n=6 /$ group). Mice from the corresponding groups were taken at $6 \mathrm{~h}$ and $12 \mathrm{~h}$ after the surgery, and then injected intraperitoneally with $\mathrm{D}$-firefly luciferin potassium salt (substrate) at $15 \mathrm{mg} / \mathrm{mL}$, $10 \mu \mathrm{L} / \mathrm{g}$, according to the instructions. After $20 \mathrm{~min}$, in vivo imaging was performed to observe and analyze cell homing.

Thirty-six mice with bone defects $(n=12 /$ group) were injected with FuT7-BMSCs and untreated BMSCs through the tail vein. The blank control group was injected with an equal volume of normal saline. At days 7 and 14, the femurs were dissected out from the defect location and analyzed by Micro-CT (PerkinElmer, USA). The defect area, Bone volume (BV)/ Tissue volume (TV) ratio, and other parameters were determined.

Eighteen mice with bone defects ( $n=6 /$ group) were injected with FuT7-BMSCs and untreated BMSCs through the tail vein. The blank control group was injected with an equal volume of normal saline. On day 10 , the femurs containing bone defects were removed, the soft tissues around the femurs were cleaned, and the femurs were then fixed in $4 \%$ paraformaldehyde for three days. The femurs were decalcified in the ethylene diamine tetraacetie acid (EDTA) solution (Solarbio, Beijing, China) for approximately $14 \mathrm{~d}$, paraffin-embedded, and sectioned. Next, the sections were staining with H\&E and Masson (Solarbio, Beijing, China) according to the assay kit instructions. The specimens were then observed and imaged under a microscope to evaluate the effect of different BMSCs on bone defect repair. 


\section{Statistical analysis}

The SPSS 20.0 (IBM, USA) statistical software was used for the statistical analysis. The experimental data were expressed as the mean \pm standard deviation, and the data were analyzed using one-way analysis of variance (ANOVA). The $t$-test was used to perform the one-toone comparison between the experimental and control groups. The difference was considered to be statistically significant at $p<0.05$.

\section{Abbreviations}

BMSCs: Bone marrow mesenchymal stem cells; sLe ${ }^{X}$ : Sialyl Lewis-X; MSCs: Mesenchymal stem cells; HSPCs: Hematopoietic stem cells; IL-1: Interleukin-1; TNF-a: Tumor necrosis factor-alpha; FuT7: Fucosyltransferase VII; GFP: Green fluorescence.

\section{Supplementary Information}

The online version contains supplementary material available at https://doi. org/10.1186/s12951-021-00969-3.

Additional file 1: Figure S1. Schematic diagram of the glycosylated BMSCs migration experiment in vitro.

\section{Acknowledgements}

Not applicable

\section{Authors' contributions}

$L C, W L$ and YW contributed equally to this work. LS and JW conceived the design of the study. LC, WL and YW collected the data and were involved in design of the study. LC, WL, YW, SL and XS contributed to data analysis and the preparation of the manuscript. LS and JW edited the manuscript. All authors have given approval to the final version of the manuscript to be published. All authors read and approved the final manuscript.

\section{Funding}

The project was supported by the National Natural Science Foundation of China (No. 81960404 and No. 81960401), Guizhou Province Science and Technology Project ([2019]1429) and Guizhou Province High-level Overseas Talents Innovation and Entrepreneurship Project (Grant No. (2019) 05).

\section{Availability of data and material}

Not applicable.

\section{Declarations}

Ethics approval and consent to participate

Not applicable.

\section{Consent for publication}

Not applicable.

\section{Competing interests}

The authors declare that they have no competing interests.

Received: 29 June 2021 Accepted: 22 July 2021

Published online: 31 July 2021

\section{References}

1. Yagi H, Soto-Gutierrez A, Parekkadan B, Kitagawa Y, Tompkins RG, Kobayashi N, Yarmush ML. Mesenchymal stem cells: mechanisms of immunomodulation and homing. Cell Transplant. 2010;19(6):667-79.
2. Karp JM, Leng Teo GS. Mesenchymal stem cell homing: the devil is in the details. Cell Stem Cell. 2009;4(3):206-16.

3. Chen L, Wu J, Wu C, Xing F, Li L, He Z, Peng K, Xiang Z. Three-dimensional co-culture of peripheral blood-derived mesenchymal stem cells and endothelial progenitor cells for bone regeneration. J Biomed Nanotechnol. 2019;15(2):248-60.

4. Peng J, Chen L, Peng K, Chen X, Wu J, He Z, Xiang Z. Bone marrow mesenchymal stem cells and endothelial progenitor cells co-culture enhances large segment bone defect repair. J Biomed Nanotechnol. 2019;15(4):742-55.

5. Fong EL, Chan CK, Goodman SB. Stem cell homing in musculoskeletal injury. Biomaterials. 2011;32(2):395-409.

6. Méndez-Ferrer S, Frenette PS. Hematopoietic stem cell trafficking: regulated adhesion and attraction to bone marrow microenvironment. Ann N Y Acad Sci. 2007;1116:392-413.

7. Sackstein R, Merzaban JS, Cain DW, Dagia NM, Spencer JA, Lin CP, Wohlgemuth R. Ex vivo glycan engineering of CD44 programs human multipotent mesenchymal stromal cell trafficking to bone. Nat Med. 2008;14(2):181-7.

8. Tonetti MS, D'Aiuto F, Nibali L, Donald A, Storry C, Parkar M, Suvan J, Hingorani AD, Vallance P, Deanfield J. Treatment of periodontitis and endothelial function. N Engl J Med. 2007;356(9):911-20.

9. Laird CT, Hassanein W, O'Neill NA, French BM, Cheng X, Fogler WE, Magnani JL, Parsell D, Cimeno A, Phelps CJ, et al. P- and E-selectin receptor antagonism prevents human leukocyte adhesion to activated porcine endothelial monolayers and attenuates porcine endothelial damage. Xenotransplantation. 2018;25(2):e12381.

10. Silva M, Videira PA, Sackstein R. E-selectin ligands in the human mononuclear phagocyte system: implications for infection, inflammation, and immunotherapy. Front Immunol. 2017;8:1878.

11. Mondal N, Buffone A Jr, Neelamegham S. Distinct glycosyltransferases synthesize E-selectin ligands in human vs. mouse leukocytes. Cell Adh Migr. 2013;7(3):288-92.

12. Auvinen $K$, Jalkanen $S$, Salmi M. Expression and function of endothelial selectins during human development. Immunology. 2014;143(3):406-15.

13. Groux-Degroote $S$, Wavelet $C$, Krzewinski-Recchi MA, Portier L, Mortuaire M, Mihalache A, Trinchera M, Delannoy P, Malagolini N, Chiricolo M, et al. B4GALNT2 gene expression controls the biosynthesis of Sda and sialyl Lewis $X$ antigens in healthy and cancer human gastrointestinal tract. Int J Biochem Cell Biol. 2014;53:442-9.

14. Thankamony SP, Sackstein R. Enforced hematopoietic cell E- and L-selectin ligand (HCELL) expression primes transendothelial migration of human mesenchymal stem cells. Proc Natl Acad Sci U S A. 2011;108(6):2258-63.

15. Sackstein R. Directing stem cell trafficking via GPS. Methods Enzymol. 2010:479:93-105

16. Gallatin WM, Weissman IL, Butcher EC. A cell-surface molecule involved in organ-specific homing of lymphocytes. Nature. 1983;304(5921):30-4.

17. Pacelli S, Basu S, Whitlow J, Chakravarti A, Acosta F, Varshney A, Modaresi S, Berkland C, Paul A. Strategies to develop endogenous stem cell-recruiting bioactive materials for tissue repair and regeneration. Adv Drug Deliv Rev. 2017;120:50-70.

18. Ullah M, Liu DD, Thakor AS. Mesenchymal stromal cell homing: mechanisms and strategies for improvement. iScience. 2019;15:421-38.

19. Mimura $Y$, Katoh T, Saldova R, O'Flaherty R, Izumi T, Mimura-Kimura Y, Utsunomiya T, Mizukami Y, Yamamoto K, Matsumoto T, Rudd PM. Glycosylation engineering of therapeutic lgG antibodies: challenges for the safety, functionality and efficacy. Protein Cell. 2018;9(1):47-62.

20. Sarkar D, Spencer JA, Phillips JA, Zhao W, Schafer S, Spelke DP, Mortensen LJ, Ruiz JP, Vemula PK, Sridharan R, et al. Engineered cell homing. Blood. 2011;118(25):e184-191. 
21. Jones GN, Moschidou D, Lay K, Abdulrazzak H, Vanleene M, Shefelbine SJ, Polak J, de Coppi P, Fisk NM, Guillot PV. Upregulating CXCR4 in human fetal mesenchymal stem cells enhances engraftment and bone mechanics in a mouse model of osteogenesis imperfecta. Stem Cells Transl Med. 2012;1(1):70-8

22. Cheng Z, Ou L, Zhou X, Li F, Jia X, Zhang Y, Liu X, Li Y, Ward CA, Melo LG, Kong D. Targeted migration of mesenchymal stem cells modified with
CXCR4 gene to infarcted myocardium improves cardiac performance. Mol Ther. 2008;16(3):571-9.

\section{Publisher's Note}

Springer Nature remains neutral with regard to jurisdictional claims in published maps and institutional affiliations.
Ready to submit your research? Choose BMC and benefit from:

- fast, convenient online submission

- thorough peer review by experienced researchers in your field

- rapid publication on acceptance

- support for research data, including large and complex data types

- gold Open Access which fosters wider collaboration and increased citations

- maximum visibility for your research: over $100 \mathrm{M}$ website views per year

At BMC, research is always in progress.

Learn more biomedcentral.com/submissions 